\title{
The Impact of Aluminum- and Iron-Bearing Admixtures on the Resistance of Portland Cement Mortars to Alkali-Silica Reaction and Sulfate Attack
}

\author{
Alexey Brykov ${ }^{*}$, Anna Anisimova1, Natalya Rozenkova1, Mohammed Hadi², \\ Maxim Mokeev ${ }^{3}$ \\ ${ }^{1}$ Department of Chemistry of Substances and Materials, Saint-Petersburg State Institute of Technology, \\ St. Petersburg, Russia \\ ${ }^{2}$ Thi-Qar University, Nasiriyah, Iraq \\ ${ }^{3}$ Institute of Macromolecular Compounds, St. Petersburg, Russia \\ Email: ${ }^{*}$ brykov@yahoo.com
}

Received 14 May 2015; accepted 13 June 2015; published 16 June 2015

Copyright (C) 2015 by authors and Scientific Research Publishing Inc.

This work is licensed under the Creative Commons Attribution International License (CC BY).

http://creativecommons.org/licenses/by/4.0/

(c) () Open Access

\section{Abstract}

Study of sulfate resistance of mortars with aluminum- and iron-bearing admixtures $\left(\mathrm{Al}(\mathrm{OH})_{3}\right.$, $\left.\mathrm{Al}_{2}\left(\mathrm{SO}_{4}\right)_{3}, \mathrm{FeSO}_{4}, \mathrm{Fe}_{2}\left(\mathrm{SO}_{4}\right)_{3}\right)$ in conditions close to those established in ASTM C 1012, and the study of the mitigation effect of these admixtures on alkali-silica reaction in accordance with accelerated "mortar bar" test ( GOST 8269.0, ASTM C 1260) were performed. Iron (II) and (III) sulfates show ability for mitigation alkali-silica reaction, while also, in contrast with Al-bearing substances, do not induce the drastic reducing of the initial setting time and do not promote the progress of sulfate corrosion. Compared with $\mathrm{FeSO}_{4}$, iron (III) sulfate has moderate deleterious impact on the early strength of cement paste and can be of interest alone as an inhibitor of ASR. Iron (II) sulfate may be used together with aluminum sulfate to offset the accelerating effect of the latter on the setting of cement paste and to reduce a risk of sulfate corrosion. During prolonged water storage, the mortar elongation and secondary ettringite formation do not occur, even when $\mathrm{Al}_{2}\left(\mathrm{SO}_{4}\right)_{3}$ is available. Therefore, the investigated admixtures cannot act as agents of internal sulfate attack, however, $\mathrm{Al}_{2}\left(\mathrm{SO}_{4}\right)_{3}$ can enhance the outer sulfate attack.

\section{Keywords}

Alkali-Silica Reaction, Sulfate Attack, Mitigation, Aluminum Sulfate, Iron Sulfate, Portland Cement

"Corresponding author.

How to cite this paper: Brykov, A., Anisimova, A., Rozenkova, N., Hadi, M. and Mokeev, M. (2015) The Impact of Aluminumand Iron-Bearing Admixtures on the Resistance of Portland Cement Mortars to Alkali-Silica Reaction and Sulfate Attack. Materials Sciences and Applications, 6, 539-548. http://dx.doi.org/10.4236/msa.2015.66058 


\section{Introduction}

Alkali-silica reaction (ASR) between pore liquid and reactive siliceous aggregate is often the cause of premature failure of Portland cement concrete structures [1]. To prevent ASR, aggregates without reactive siliceous inclusions, as well as partial replacement of cement with active mineral additives, are used at present [2]. In a number of countries lithium compounds (preferably, $\mathrm{LiNO}_{3}$ ) are used as inhibitors of ASR [3]. Among the disadvantages of these methods, there are deficit of high-grade aggregates, a high cost of lithium compounds, a need to use mineral additives at large dosages which have adverse side effects on the properties of mortars and concretes. Therefore, other methods are actively studied related to ASR inhibiting [4]. It was shown in [5] that aluminum-containing compounds-amorphous hydroxide, sulfate and basic sulfate-possess the ability to mitigate ASR. However, their usage in this field is complicated by the following features:

- aluminum-bearing compounds cause rapid setting of cement paste; high dosages of aluminum compounds result in reduced early strength of cement [6] [7];

- aluminum-bearing compounds can promote sulfate corrosion of cement mortars and concretes provided that there is an additional intake of sulfate ions from the environment [8] [9].

It has been possible to overcome the first of these disadvantages by partial substitution of the aluminum compound (namely, aluminum sulfate) with iron (II) sulfate. The combined use of aluminum sulfate and iron (II) sulfate allowed (along with an effective inhibitory effect) for initial setting of cement paste in typical time limits and to keep early and mature strength on the level of reference samples [5].

The possibility of the development of sulfate corrosion provoked by aluminum-containing admixtures makes it necessary to continue the researches of aluminum and iron compounds, both as inhibitors of ASR and as potential participants of the destructive processes which underlie the sulfate corrosion. With regard to the prevention of the sulfate corrosion, iron-containing compounds may be the future, as it is known, for example, that Fe-substituted ettringite does not cause such significant stresses during its formation in the pore structure of cement stone as iron-depleted ettringite [10] [11]. Furthermore, in cement technology iron (II) sulfate is used as admixture for reducing $\mathrm{Cr}(\mathrm{VI})$ to $\mathrm{Cr}(\mathrm{III})$ [12]; iron salts are also mentioned as alkali-aggregate expansion reducers in [13].

The objective of this work, being the sequel of the recent works [5] [8], consists in a comparative study of effect of aluminum sulfate, iron (II) and iron (III) sulfates on alkali-silica expansion of cement mortars containing reactive siliceous aggregate in accordance with accelerated "mortar-bar" method (GOST 8269.0, ASTM C 1260) and on sulfate resistance of mortars according to the methodology close to ASTM C 1012. ${ }^{27} \mathrm{Al}$-MAS NMR spectroscopy was used when studying processes occurring in cement pastes with the investigated admixtures during sulfate resistance test. The influence of the investigated admixtures on setting time and strength of cement paste was also studied

\section{Experimental Part}

In this work, iron (III) sulfate hydrate $\mathrm{Fe}_{2}\left(\mathrm{SO}_{4}\right)_{3} \cdot 9 \mathrm{H}_{2} \mathrm{O}$, chemically pure, was used as $\mathrm{Fe}(\mathrm{III})$-bearing admixture. For sulfate resistance test, usual quartz-feldspar sand with fineness modulus of 1.5 was used as mortar aggregate. Other materials (Portland cement, burned sand for ASR test, aluminum-and iron (II)-bearing admixtures) were the same as in our previous work [8]. An additional point is that natural sand with high content of chalcedony $(\sim 40 \%)$ was used in ASR test as an alternative to burned sand. The particle size distribution of these two aggregates was the same [8].

The values of initial setting time of cement pastes with investigated admixtures at w/c 0.4 were determined in accordance with GOST 310.3-76. Aluminum-bearing substances were taken in dosages to be equimolar to the preset values of the $\mathrm{Al}_{2} \mathrm{O}_{3}$ content of cement weight, e.g., the dosage of $1 \mathrm{wt} \% \mathrm{Al}_{2} \mathrm{O}_{3}$ corresponds to $6.0 \mathrm{wt} \%$ of aluminum sulfate hydrate (ALG, "KemiraOyj", $\mathrm{Al}_{2} \mathrm{O}_{3} 17.0$ wt\%). Iron (II) sulfate 7-hydrate and iron (III) sulfate 9-hydrate recalculated for $\mathrm{Fe}_{2} \mathrm{O}_{3}$ were taken in quantities to be equimolar to the preset values of the $\mathrm{Al}_{2} \mathrm{O}_{3}$ content of cement weight (e.g., the dosage of $5.5 \% \mathrm{FeSO}_{4} \cdot 7 \mathrm{H}_{2} \mathrm{O}$ or $\mathrm{Fe}_{2}\left(\mathrm{SO}_{4}\right)_{3} \cdot 9 \mathrm{H}_{2} \mathrm{O}$ of the cement weight in terms of $\mathrm{Fe}_{2} \mathrm{O}_{3}$ is equimolar to $1 \mathrm{wt} \% \mathrm{Al}_{2} \mathrm{O}_{3}$ ). In some compositions the complex admixtures containing aluminum sulfate together with iron (II) or iron (III) sulfate were used. All the admixtures were preliminarily dissolved in the water of mixing. The hydrate water in admixtures was taken into account.

For studying of compressive strength, cement pastes were placed into the cube forms of $30 \times 30 \times 30 \mathrm{~mm}$. The forms were stored above water in sealed container at $18^{\circ} \mathrm{C}$. After 1 day, the hardened samples were demoulded; 
the subsequent storage was accomplished under the same conditions. Compressive strength tests were carried out at the age of 1 and 28 days. Each strength value was calculated as an average value of 4 - 6 samples.

Alkali-silica reaction test (accelerated "mortar bar" test) for mortars with admixtures was accomplished in the same manner as in our previous work [5].

An impact of investigated admixtures on sulfate resistance of mortars was studied following the method close to that described in ASTM C 1012 "Length Change of Hydraulic-Cement Mortars Exposed to a Sulfate Solution". A reference mortar mix was prepared by mixing sand with cement at weight ratio of 2.75:1, water-tocement ratio was 0.485 . Mixtures with aluminum- and iron-bearing admixtures at equimolar dosages (in terms of $\mathrm{Al}_{2} \mathrm{O}_{3}$ or $\mathrm{Fe}_{2} \mathrm{O}_{3}$ ) to the some preset values of $\mathrm{Al}_{2} \mathrm{O}_{3}$ content of cement weight were similarly prepared. Amorphous $\mathrm{Al}(\mathrm{OH})_{3}$ "Geloxal", which being used in [8], has been also investigated and has been pre-mixed with dry components. Aluminum and iron (II) and (III) sulfates were introduced in cement-sand mix while being dissolved in mixing water (in ASR test, the admixtures were introduced in the same manner). The hydrate water of the admixtures was taken into account to calculate w/c.

Mortar mixes prepared were casted into prism (bar) moulds of $20 \times 20 \times 100 \mathrm{~mm}$ and cube moulds of $30 \times 30$ $\times 30 \mathrm{~mm}$. The samples were stored above water in a sealed container at $20^{\circ} \mathrm{C} \pm 2^{\circ} \mathrm{C}$ for 1 day. After that, samples were demolded and stored in distilled water until the compressive strength of cubic samples of at least $20 \mathrm{MPa}$ is reached (3 - 7 days). Subsequently, the initial length of bars was measured. Half of bars for each series were stored in distilled water and the rest is in sulfate solution $\left(5 \% \mathrm{Na}_{2} \mathrm{SO}_{4}\right)$. Measurements of expansion of mortar bars and replacement of sodium sulfate solution have been done on a weekly basis. For each mix two bars were made; an average value of elongation of two samples is taken as a final measurement result.

For ${ }^{27} \mathrm{Al}-\mathrm{MAS}$ NMR analysis, the same compositions were prepared without sand (i.e. in the form of cement pastes) and moulded in the form of tablets with diameter of $50 \mathrm{~mm}$ and thickness of $3-4 \mathrm{~mm}$. Storage conditions were close to ones for bars-storing for 1 day above water and 6 days submerged in distilled water; after that each sample has been divided into two pieces: one piece has been kept stored under the water for 28 days over, and another piece was submerged into sulfate solution over the same period of time. The spectral analyses were carried out on cement paste samples of 6 days of preliminary storing under water and for 28 days cement pastes stored both in water and sodium sulfate solution. For analyses, some part of cement paste sample ( $\sim \mathrm{g}$ ) was powdered and washed with acetone and then vacuum-dried at ambient temperature.

High-resolution solid-state ${ }^{27} \mathrm{Al}$-MAS NMR spectra have been obtained using AVANCE II-500WB (Bruker) spectrometer with "magic angle" spinning. Operating frequency for ${ }^{27} \mathrm{Al}$ was $130.32 \mathrm{MHz}$. Spectra were recorded by single-pulse excitation, the pulse duration of $0.7 \mu \mathrm{s}(\pi / 12)$ with a delay of $0.5 \mathrm{sec}$. was used, and number of scans was 2048. The samples material ( 100 mg) were packed in zirconia rotors (D $4 \mathrm{~mm}$ ) and rotated at $13 \mathrm{kHz}$. Chemical shifts are given in ppm relative to $\mathrm{AlCl}_{3} \cdot 6 \mathrm{H}_{2} \mathrm{O}$. The assignment of the signals is accomplished in accordance with the published data [14]. The deconvolution of spectra was performed by means of Dmfit software. Signal intensities in ${ }^{27} \mathrm{Al}-\mathrm{NMR}$ spectra are given in the absolute scale (similar measurement conditions), which allows them to be compared with each other.

\section{Results and Discussion}

Table 1 shows initial setting time of fresh cement pastes and compressive strength of hardened ones. As can be seen, aluminum sulfate, iron (II) and iron (III) sulfates reduce the initial setting time of cement paste in 1.5 to 60 times, depending on the type and dosage of admixtures. Aluminum sulfate accelerates setting to the most extent; at the dosage of 0.5 and $1 \mathrm{wt} \%$ relevant to $\mathrm{Al}_{2} \mathrm{O}_{3}$ initial setting time is 15 and less than 5 min, correspondingly. Aluminum sulfate at the dosage of $1 \%$ also contributes to increasing in strength of cement paste at 1-day age.

For iron (II) and (III) sulfates, the setting time depends on the admixture content in different manner. In the case of $\mathrm{Fe}_{2}\left(\mathrm{SO}_{4}\right)_{3}$, the increase of the admixture dosage from 0.25 to $1 \%$ leads to the decrease of the initial setting time (from 210 to $70 \mathrm{~min}$ ), whereas for the same dosages of $\mathrm{FeSO}_{4}$ the initial setting time increases from 15 to $50 \mathrm{~min}$. The shortening of setting time in the presence of iron sulfates may be due to formation of insoluble $\mathrm{Fe}(\mathrm{OH})_{2}$ and $\mathrm{Fe}(\mathrm{OH})_{3}$ as well as due to partial participation of sulfate admixtures in formation of Fe-doped ettringite (AFt phase) and other phases. One should also take into account the hydrolysis of $\mathrm{Fe}_{2}\left(\mathrm{SO}_{4}\right)_{3}$ in aqueous solution and destabilization of $\mathrm{pH}$ of cement paste by introducing admixtures.

Iron (II) and (III) sulfates, along with reducing the setting time of cement paste, however, also reduce its early strength. In the presence of iron (II) sulfate, the strength of cement paste at 1-day age is close to 0 for any dosage. In the case of iron (III) sulfate, increasing dosage from 0.25 to $1 \%$, increases the strength from 2 to $5 \mathrm{MPa}$. 
Table 1. Initial setting time and compressive strength of cement pastes with aluminum-and iron-bearing admixtures (w/c 0.4).

\begin{tabular}{|c|c|c|c|}
\hline \multirow{2}{*}{$\begin{array}{l}\text { The admixture content, \% of cement weight } \\
\text { (in parentheses the admixture content recalculated to } \\
\mathrm{Al}_{2} \mathrm{O}_{3}, \% \text { of cement weight, is shown) }\end{array}$} & \multicolumn{3}{|c|}{ Compressive strength, MPa, at the age, days } \\
\hline & Initial setting time, min & 1 & 28 \\
\hline Reference paste & 300 & 6.7 & 47.0 \\
\hline \multicolumn{4}{|l|}{$\mathrm{Al}_{2}\left(\mathrm{SO}_{4}\right)_{3}$ hydrated } \\
\hline $3.0(0.5)$ & 15 & 7.1 & 62.3 \\
\hline $6.0(1.0)$ & $<5$ & 9.7 & 47.2 \\
\hline \multicolumn{4}{|l|}{$\mathrm{FeSO}_{4} \cdot 7 \mathrm{H}_{2} \mathrm{O}$} \\
\hline $1.35(0.25)$ & 15 & 0.0 (at 2 days -1.3 ) & 58.1 \\
\hline $2.7(0.5)$ & 35 & 0.0 & 45.0 \\
\hline $5.4(1.0)$ & 50 & 0.3 & 50.9 \\
\hline \multicolumn{4}{|l|}{$\mathrm{Al}_{2}\left(\mathrm{SO}_{4}\right)_{3}$ hydrated $/ \mathrm{FeSO}_{4} \cdot 7 \mathrm{H}_{2} \mathrm{O}$} \\
\hline 4.1/1.6 (0.7/0.3) & 5 & - & - \\
\hline $3.6 / 2.2(0.6 / 0.4)$ & 20 & 5.2 & 36.5 \\
\hline $3.0 / 2.7(0.5 / 0.5)$ & 50 & 5.0 & 50.3 \\
\hline 3.6/3.2 (0.6/0.6) & 20 & 6.1 & 61.0 \\
\hline $2.4 / 1.6(0.4 / 0.3)$ & 75 & 3.7 & 49.4 \\
\hline \multicolumn{4}{|l|}{$\mathrm{Fe}_{2}\left(\mathrm{SO}_{4}\right)_{3} \cdot 9 \mathrm{H}_{2} \mathrm{O}$} \\
\hline $1.35(0.25)$ & 210 & 1.7 (at 2 days -7.0 ) & 59.5 \\
\hline $2.7(0.5)$ & 195 & 3.7 & - \\
\hline $5.4(1.0)$ & 70 & 5.3 & 51.7 \\
\hline \multicolumn{4}{|l|}{$\mathrm{Al}_{2}\left(\mathrm{SO}_{4}\right)_{3}$ hydrated/Fe $2\left(\mathrm{SO}_{4}\right)_{3} \cdot 9 \mathrm{H}_{2} \mathrm{O}$} \\
\hline $3.0 / 2.75(0.5 / 0.5)$ & 15 & 6.6 & 60.7 \\
\hline
\end{tabular}

Apparently, a highly dispersed iron hydroxides have a screening effect on the clinker phases with subsequent retardation of hydration and curing, but this effect is not the same for iron (II) and iron (III). In the case of iron (II) the screening effect is more pronounced because finely dispersed $\mathrm{Fe}(\mathrm{OH})_{2}$ yields more impervious cover on cement particles. The above mentioned increase of initial setting time with increasing $\mathrm{FeSO}_{4}$ dosage may also be attributable to screening effect. In the case of $\mathrm{Fe}(\mathrm{III})$, the deceleration of hydration while increasing in admixture dosage is compensated by clogging pores and sealing structure with products formed, which is then followed by strength increasing. At the age of 1 month the strength of cement paste with the addition of iron (II) and (III) sulfates corresponds to the strength of the reference sample or even exceeds it.

Table 1 shows also the setting time and compressive strength of cement paste when co-introducing aluminum and iron sulfates. It can be seen that an increase of substitution degree of aluminum sulfate with iron (II) sulfate is accompanied by an increase of the initial setting time. Thus, the cement paste with aluminum sulfate $\left(\mathrm{Al}_{2} \mathrm{O}_{3} 1\right.$ wt\%) sets within $5 \mathrm{~min}$; the replacing of half aluminum sulfate by equimolar amount of iron (II) sulfate (recalculated to $\mathrm{Fe}_{2} \mathrm{O}_{3}$ ) leads to the increase of the initial setting time up to 50 min. At the same time, the negative influence of iron (II) sulfate on the early strength of cement paste is compensated by accelerating effect of aluminum sulfate, so that 1-day strength in this case is only slightly less than for reference sample.

A partial substitution of aluminum sulfate with iron (III) sulfate does not increase the initial setting time of the cement paste in comparison with paste containing aluminum sulfate alone.

Figure 1 shows the time dependence of ASR expansion of mortar samples in which burned sand as reactive aggregate has been used. Figure 2 presents the same behavior for mortars with natural chalcedony sand as aggregate.

As seen in Figure 1 and Figure 2, iron (II) and (III) sulfates exhibit an ability to mitigate alkali-silica reaction. Suppression of ASR appears to be due to colmatation of pores and sealing the structure with poorly soluble iron (II) and (III) hydroxides as well as due to involving Fe-ions in the binding of calcium ions into AFt and other phases to some extent. The low rate of the early strength development of cement paste with iron (II) sulfate 
imposes a limit on its significance as a solo ASR inhibitor; at the same time, it may be coupled with aluminum sulfate to balance the accelerating effect of the latter on cement paste setting [8]. The dosage of two sulfates $-2.7 \% \mathrm{FeSO}_{4} \cdot 7 \mathrm{H}_{2} \mathrm{O}$ and $3.0 \% \mathrm{Al}_{2}\left(\mathrm{SO}_{4}\right)_{3}\left(0.5 / 0.5 \mathrm{wt} \%\right.$ in terms of $\left.\mathrm{Al}_{2} \mathrm{O}_{3}\right)$-along with an effective ASR mitigating effect allows for initial setting time of cement paste to remain in usual limits and helps keeping of the early and late strength values on the level of reference cement paste.

Comparing to $\mathrm{FeSO}_{4}$, iron (III) sulfate has a minimal negative impact on the early strength, reducing it by only $20 \%$ - $45 \%$ relative to the reference strength values. Thus, iron sulfate (III) can be used alone as an inhibitor of ASR. At the same time, the combined use of iron (III) sulfate with aluminum sulfate reduces substantially the setting time of cement paste, as with sole aluminum sulfate.

The results of sulfate expansion test are shown in Figure 3. Under water curing conditions the elongation of samples occur neither in case of reference sample nor in case of samples with admixtures (Figure 3(a)). Meanwhile, when stored in sulfate solution (Figure 3(b)), all the mortars elongated, the least elongation was shown by the reference mortar (up to $0.4 \%$ ), the most elongated one being the mortar bar with $\mathrm{Al}_{2}\left(\mathrm{SO}_{4}\right)_{3}$ (up to $2 \%$ ).

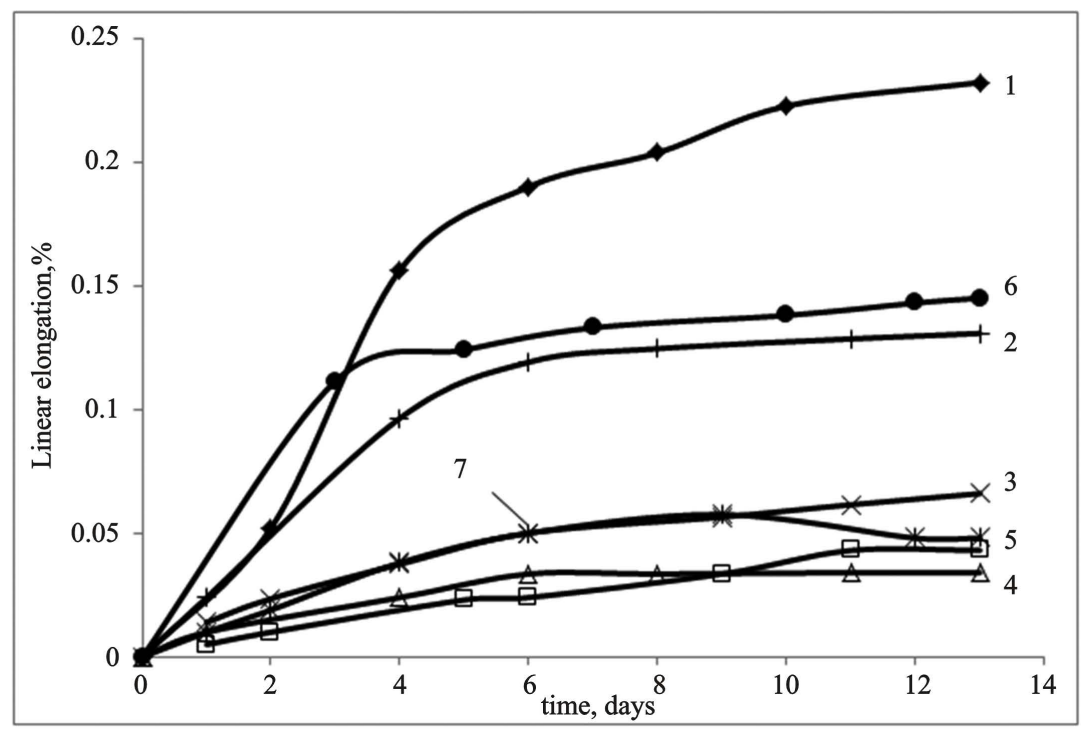

Figure 1. Linear elongation $\varepsilon(\%)$ of mortar bars containing reactive burned sand in $1 \mathrm{M} \mathrm{NaOH}$ versus time (days): 1 -reference mortar without admixtures; (2, 3)-with $\mathrm{Al}_{2}\left(\mathrm{SO}_{4}\right)_{3}$ at dosage of 0.5 and $1 \mathrm{wt} \%$, correspondingly; $(4,5)$-with $\mathrm{FeSO}_{4}$ and $\mathrm{Fe}_{2}\left(\mathrm{SO}_{4}\right)_{3}$, correspondingly, (0.5 wt\%); (6, 7)-complex admixture $\mathrm{Al}_{2}(\mathrm{SO} 4)_{3} / \mathrm{FeSO}_{4}$ at dosage of 0.4/0.3 and 0.5/0.5 wt\%, correspondingly (the admixture dosages are given in terms of $\mathrm{Al}_{2} \mathrm{O}_{3}$ ).

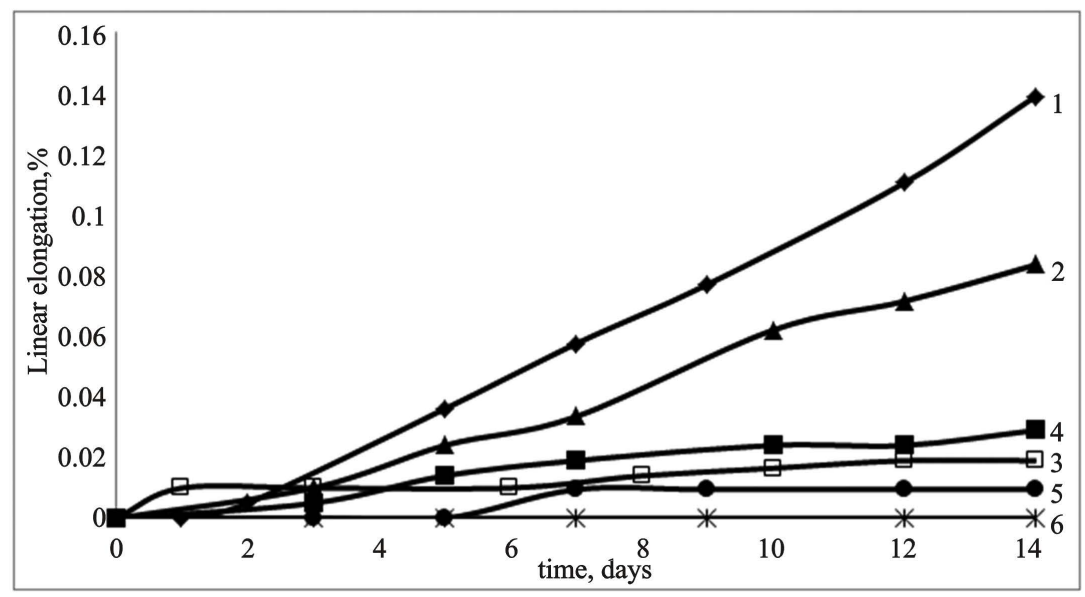

Figure 2. Linear elongation $\varepsilon(\%)$ of mortar bars containing reactive natural chalcedony sand in $1 \mathrm{M} \mathrm{NaOH}$ versus time (days): 1-reference mortar without admixtures; 2- $\mathrm{Al}(\mathrm{OH})_{3}, 3-\mathrm{I}_{2}\left(\mathrm{SO}_{4}\right)_{3}, 4-\mathrm{Al}_{2}\left(\mathrm{SO}_{4}\right)_{3} / \mathrm{FeSO}_{4}(0.5 / 0.5 \%),(5,6)-\mathrm{Fe}_{2}\left(\mathrm{SO}_{4}\right)_{3}$ at dosage of 1 and $0.5 \%$, correspondingly (the admixture dosages are given in terms of $\mathrm{Al}_{2} \mathrm{O}_{3}$ ). 


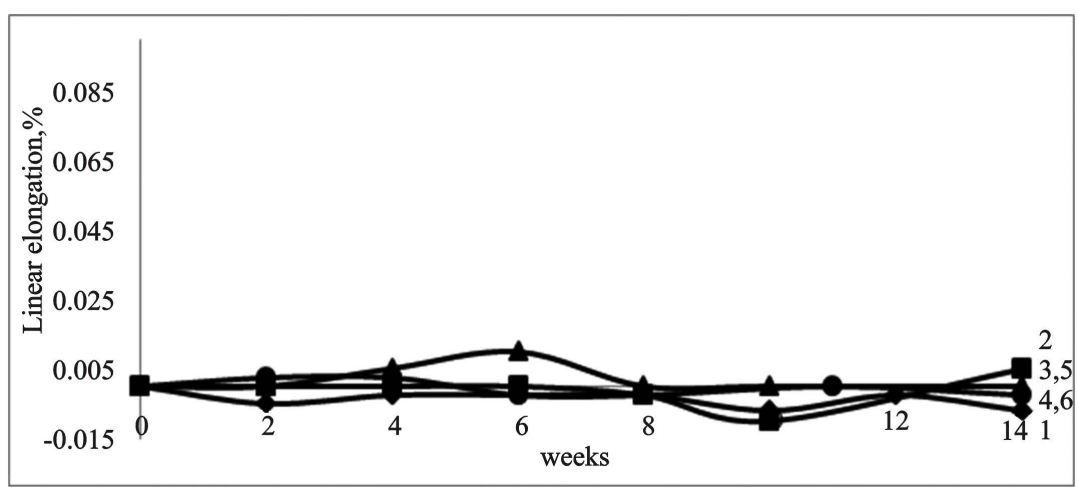

(a)

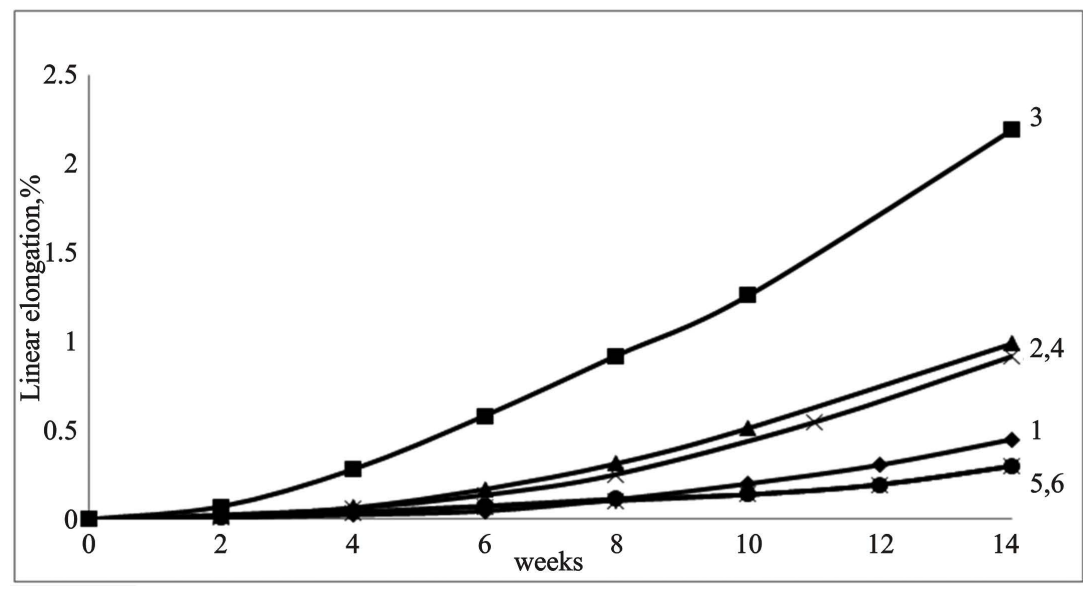

(b)

Figure 3. Linear elongation of the reference mortar (1) and mortars with $\mathrm{Al}(\mathrm{OH})_{3}(2), \mathrm{Al}_{2}\left(\mathrm{SO}_{4}\right)_{3}(3), \mathrm{Al}_{2}\left(\mathrm{SO}_{4}\right)_{3}+\mathrm{FeSO}_{4}(4)$, $\mathrm{Fe}_{2}\left(\mathrm{SO}_{4}\right)_{3} 0.5$ and $1 \%(5,6)$, (a) storage in water; (b) storage in sodium sulfate solution.

Partial substitution of $\mathrm{Al}_{2}\left(\mathrm{SO}_{4}\right)_{3}$ by $\mathrm{FeSO}_{4} \cdot 7 \mathrm{H}_{2} \mathrm{O}$ leads to the diminution of elongation to the level of about $1 \%$. The elongation curve of the mortar with iron (III) sulfate coincides well with the reference curve. Therefore, iron (II) and (III) sulfates, in contrast with Al-bearing substances, do not induce the drastic reducing of the initial setting time and do not promote the progress of sulfate corrosion.

Figure 4 shows the ${ }^{27}$ Al-MAS NMR spectra of cement pastes with and without admixtures at various exposure times and environment conditions. Fragments of the spectra in range of 50 - 90 ppm (an area of 4-coordinated $\mathrm{Al}$ ) are given in the enlarged scale.

On samples' spectra there is an intensive signal at 14.7 - $15.2 \mathrm{ppm}$ which is characteristic for AFt phase, or ettringite $\left(3 \mathrm{CaO} \cdot \mathrm{Al}_{2} \mathrm{O}_{3} \cdot 3 \mathrm{CaSO}_{4} \cdot 32 \mathrm{H}_{2} \mathrm{O}\right)$. The less intensive signal to the right of the ettringite signal (11 - 12 ppm) belongs to AFm phase, i.e. calcium monosulfoaluminate $\left(3 \mathrm{CaO} \cdot \mathrm{Al}_{2} \mathrm{O}_{3} \cdot \mathrm{CaSO}_{4} \cdot 12 \mathrm{H}_{2} \mathrm{O}\right)$, which is produced by an interaction of ettringite with products of dissolution of $\mathrm{C}_{3} \mathrm{~A}$ and $\mathrm{C}_{4} \mathrm{AF}$. To the right of this signal the shoulder appears (6 - $7 \mathrm{ppm}$ ) indicating the formation of hydrated calcium aluminates (attributed also to AFm) due to direct hydration of $\mathrm{C}_{3} \mathrm{~A}$ and $\mathrm{C}_{4} \mathrm{AF}$. These phases contain $\mathrm{Al}$ in 6-coordinated state with oxygen.

A broad signal with a maximum at 73 - 74 ppm belongs to 4-coordinated aluminum ions incorporated into silicon-oxygen chains of the $\mathrm{C}-\mathrm{S}-\mathrm{H}$ gel ( $\mathrm{Si}-\mathrm{O}-\mathrm{Al}-\mathrm{O}-\mathrm{Si}$ bonds).

The values of integral intensity of signals in the area of 0 - 20 ppm (6-coordinated Al) shown in the Table 2 and are referred to intensity of ettringite signal of the reference sample at the age of 7 days which is taken as 1.00 .

As can be seen from Table 2, at the age of 7 days, the largest amount of ettringite is found in cement pastes with admixtures of $\mathrm{Al}_{2}\left(\mathrm{SO}_{4}\right)_{3}$ and $\mathrm{Al}_{2}\left(\mathrm{SO}_{4}\right)_{3}+\mathrm{FeSO}_{4}$. After additional 28 days of water storing, there is no significant change in ettringite content in samples compared to 7 days old samples. This fact is in agreement with the absence of mortars' elongation during water storing (Figure 3(a)). Therefore, these admixtures cannot act as 


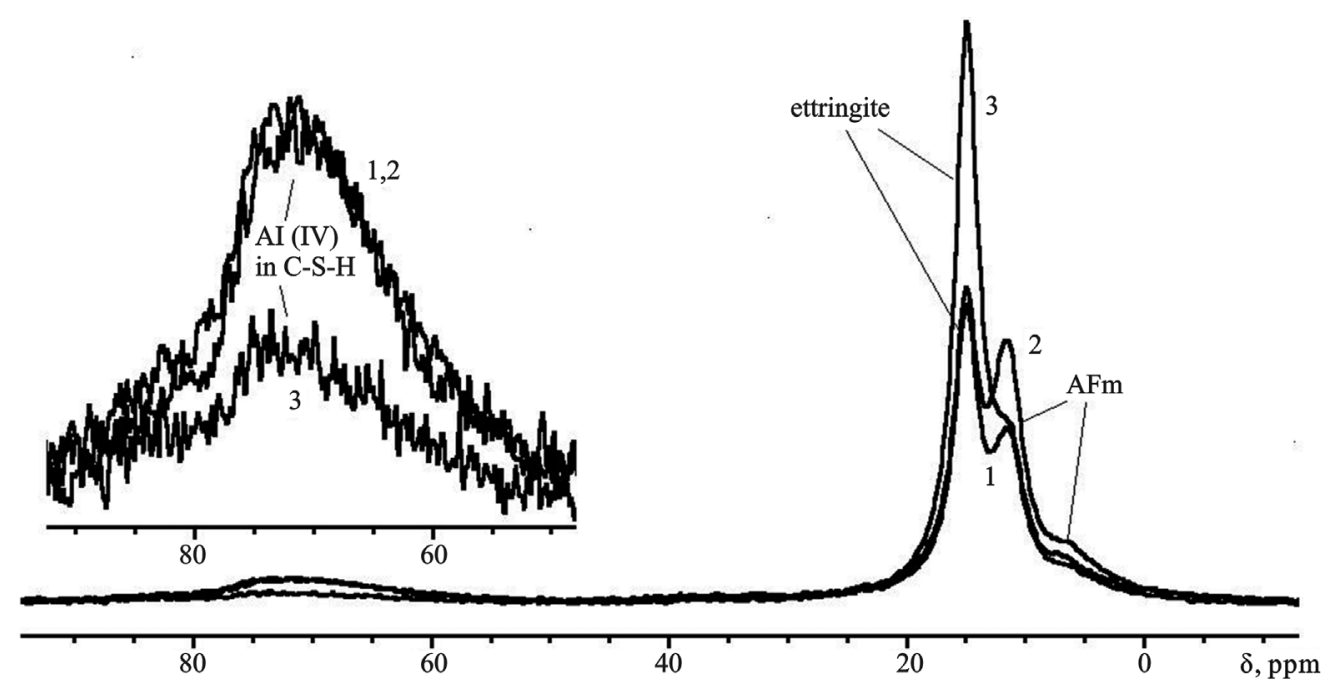

(a)

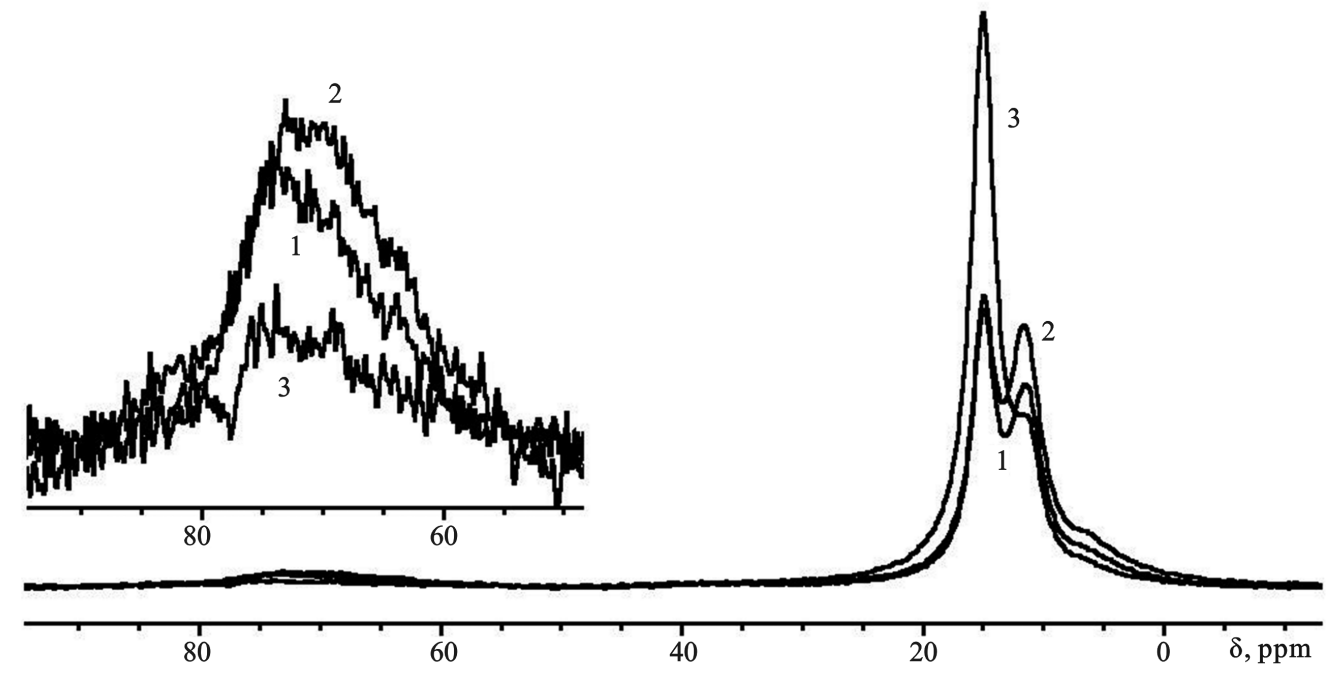

(b)

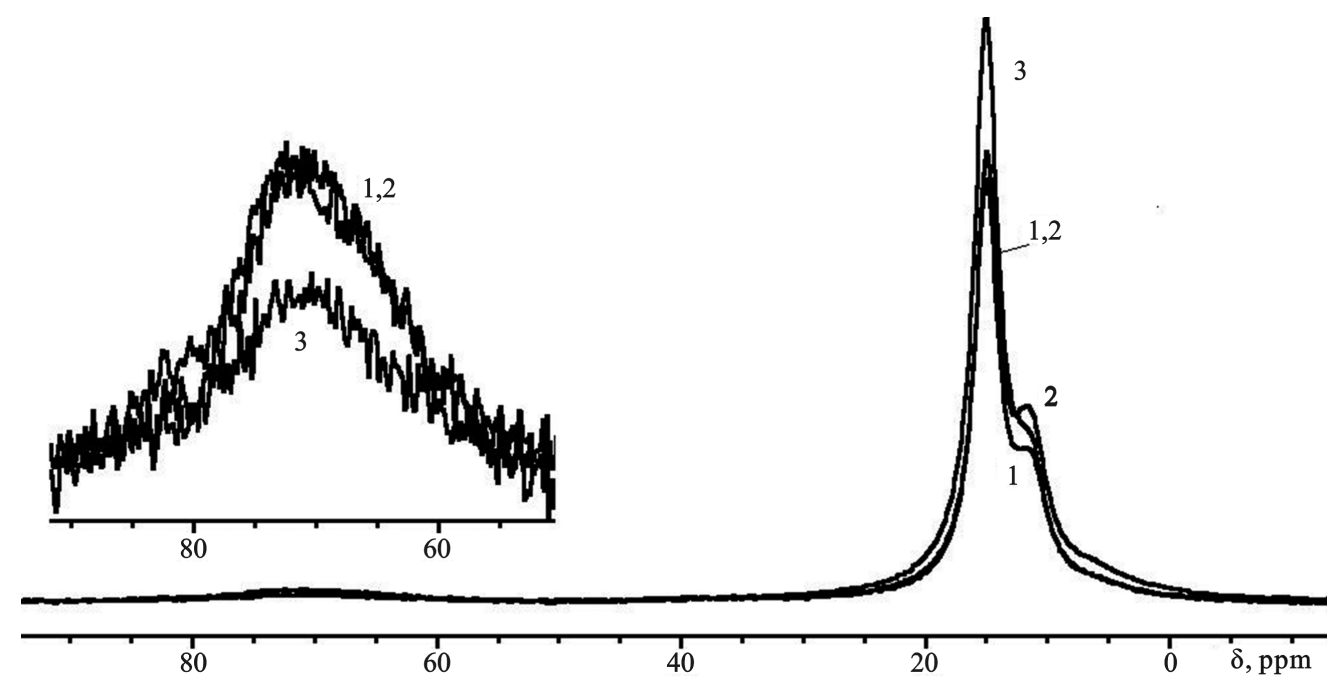

(c) 


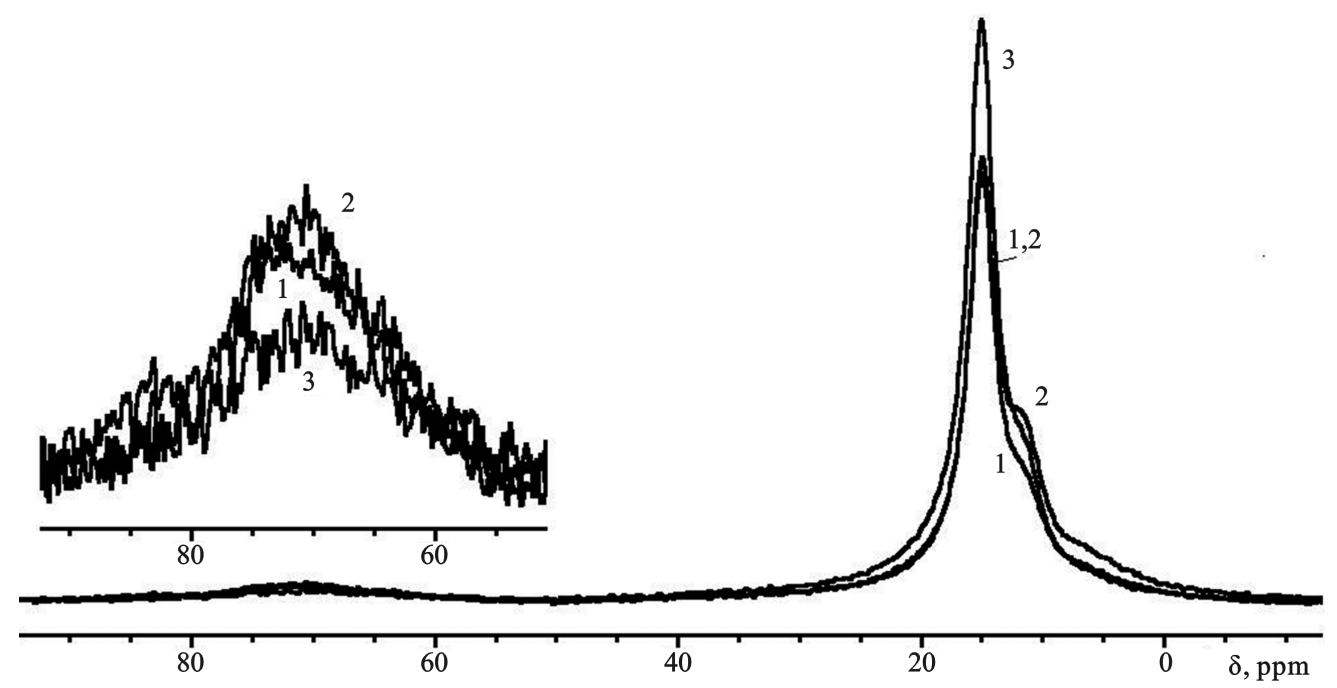

(d)

Figure 4. ${ }^{27} \mathrm{Al}$-MAS NMR spectra of cement pastes at the age: 1 -(6 days of "water" storing); $2-(6+28=34$ days of "water" storing); 3-(6 days of water storing and 28 days of "sulfate" storing). (a) reference cement paster; (b) cement paste with $\mathrm{Al}(\mathrm{OH})_{3}$; (c) cement paste with $\mathrm{Al}_{2}\left(\mathrm{SO}_{4}\right)_{3}$; (d) cement paste with $\mathrm{Al}_{2}\left(\mathrm{SO}_{4}\right)_{3}+\mathrm{FeSO}_{4}$.

Table 2. The values of integral intensity of signals of 6-coordinated Al.

\begin{tabular}{cccc} 
& & \multicolumn{2}{c}{ Preliminary storage } \\
& & \multicolumn{2}{c}{ The following storage } \\
\cline { 2 - 3 } Reference sample & $1.00^{*}$ & 28 days in water & 28 days in $\mathrm{Na}_{2} \mathrm{SO}_{4}$ \\
& 0.69 & 1.02 & 1.96 \\
& 0.16 & 1.09 & 0.68 \\
$\mathrm{Al}(\mathrm{OH})_{3}$ & 1.37 & 0.29 & 0.16 \\
& 1.31 & 1.40 & 3.14 \\
$\mathrm{Al}_{2}\left(\mathrm{SO}_{4}\right)_{3}$ & 0.26 & 1.72 & 0.81 \\
& 2.46 & 0.42 & 3.92 \\
& 0.92 & 2.52 & 0.78 \\
$\mathrm{Al}_{2}\left(\mathrm{SO}_{4}\right)_{3}+\mathrm{FeSO}_{4}$ & 0.17 & 1.25 & 0.08 \\
& 1.59 & 0.36 & 3.17 \\
\hline
\end{tabular}

*The first value in cells corresponds to ettringite (AFt) signal, second and third ones belong to calcium monosulfoaluminate and hydrated aluminates (AFm), correspondingly.

a source of secondary ettringite and they are neither agents of internal sulfate attack.

During water storage, some increasing in intensities of AFm signals is observed for all samples. Since material of admixtures depletes in the beginning of hydration [7] and the amount of ettringite does not change, the increment in AFm is only possible due to transformation of aluminate $\left(C_{3} A\right)$ and aluminoferrite $\left(C_{4} A F\right)$ phases of cement under sulfate ions deficit conditions. Meanwhile, as can be seen from Figure 4, intensity of the signal at $70 \mathrm{ppm}$ indicates that contribution of 4-coordinated $\mathrm{Al}$ into C-S-H does not change or increase slightly during water storage.

In accordance with NMR data (Table 2), during "sulfate" storage, secondary ettringite forms in all samples and that is the reason for significant elongation of samples. The highest total amount of ettringite is formed in sample with addition of aluminum sulfate, while the lowest - in the reference sample. Signal intensities of ettringite in cement pastes with $\mathrm{Al}(\mathrm{OH})_{3}$ and combined admixture of $\mathrm{Al}_{2}\left(\mathrm{SO}_{4}\right)_{3}+\mathrm{FeSO}_{4}$ are equal and fall in between highest and lowest cases. This agrees well with results of elongations reading.

Strictly speaking, cement paste with complex admixture $\mathrm{Al}_{2}\left(\mathrm{SO}_{4}\right)_{3}+\mathrm{FeSO}_{4}$ may contain higher amount of ettringite than $\mathrm{Al}(\mathrm{OH})_{3}$-paste, because $\mathrm{Fe}$ incorporates to a certain degree into ettringite along with $\mathrm{Al}$ in this 
composition. Besides of that, consideration must be given to the fact that the presence of Fe-ions in the vicinity of aluminum nuclei makes at least part of them to be "invisible" on the spectra [14]. Meanwhile, as is well known, Fe-substituted ettringite by virtue of its structural peculiarities generates less internal stress in comparison with Fe-depleted ettringite [10] [11]. As a consequence, smaller deformations and smaller strength degradation take place when compared to sample with $\mathrm{Al}_{2}\left(\mathrm{SO}_{4}\right)_{3}$.

As can be seen from spectral data, the formation of secondary ettringite is in conjunction with decrease of AFm phase content (calcium monosulfoaluminate hydrate and aluminate hydrate), as well as with the decrease of 4-coordinated Al contribution in C-S-H. Therefore, these compounds become the source of the Al-ions for the formation of secondary ettringite when $\mathrm{SO}_{4}^{2-}$ ions attack cement paste.

\section{Conclusions}

Iron (II) and (III) sulfates show ability for mitigation alkali-silica reaction, while also, in contrast with Al-bearing substances, do not induce the drastic reducing of the initial setting time and do not promote the progress of sulfate corrosion. However, iron (II) sulfate admixture significantly reduces early compressive strength of the hardened cement paste. Compared with $\mathrm{FeSO}_{4}$, iron (III) sulfate has moderate deleterious impact on the early strength of cement paste and can be of interest alone as an inhibitor of ASR.

Iron (II) sulfate may be used together with aluminum sulfate to compensate accelerating effect of the latter on cement paste setting and to reduce risk of sulfate corrosion. Introducing $\mathrm{FeSO}_{4} \cdot 7 \mathrm{H}_{2} \mathrm{O}$ and $\mathrm{Al}_{2}\left(\mathrm{SO}_{4}\right)_{3} \cdot 18 \mathrm{H}_{2} \mathrm{O}$ at dosages of $2.7 \%$ and $3.0 \%$ of cement weight respectively along with an effective mitigating effect allows for initial setting time of cement paste to stay at typical values and to keep early and late strength values on level with the reference cement paste.

Formation of secondary ettringite and expansion of the reference mortar and mortars with Al-bearing admixtures takes place only when $\mathrm{SO}_{4}^{2-}$ anions intake into mortars or cement pastes from outside. The elongation of mortars stored in sulfate solution is proportional to the total content of ettringite (primary and secondary) formed in cement pastes. The largest deformations occur for mortars with addition of $\mathrm{Al}_{2}\left(\mathrm{SO}_{4}\right)_{3}$, the least - for reference mortar.

However, during sulfate storage, formation of secondary ettringite is aligned with decrease in AFm phases (calcium monosulfoaluminate hydrate and aluminate hydrates), as well as with diminution of 4-coordinated $\mathrm{Al}$ contribution to C-S-H. Therefore, 4-coordinated $\mathrm{Al}$ in C-S-H, together with AFm phases, is the source of $\mathrm{Al}$ for secondary ettringite formation in cement pastes during sulfate storing.

That fact that iron sulfates do not promote sulfate attack is due to the decreased total quantity of ettringite and due to structural peculiarities of its Fe-doped form. Moreover, in contrast with Al-ions, Fe-ions do not contribute into silicate chains of C-S-H and, so, do not provoke secondary ettringite formation during sulfate storing.

During prolonged water storage, the mortar elongation and secondary ettringite formation do not occur, even when $\mathrm{Al}_{2}\left(\mathrm{SO}_{4}\right)_{3}$ is available. Therefore, investigated admixtures cannot act as agents of internal sulfate attack, however, $\mathrm{Al}_{2}\left(\mathrm{SO}_{4}\right)_{3}$ can enhance the outer sulfate attack rate.

\section{Acknowledgements}

Authors acknowledge a gratitude to the Ministry of Higher Education and Scientific Research of Iraq and to the University of Thi-Qar for their encouragement and support.

\section{References}

[1] Thomas, M.D.A. and Folliard, K.J. (2007) Concrete Aggregates and the Durability of Concrete. In: Page, C. and Page, M., Eds., Durability of Concrete and Cement Composites, CRC Press, New York, 403.

[2] Thomas, M. (2011) The Effect of Supplementary Cementing Materials on Alkali-Silica Reaction: A Review. Cement and Concrete Research, 41, 1224-1231. http://dx.doi.org/10.1016/j.cemconres.2010.11.003

[3] Thomas, M., Fournier, B., Folliard, K., et al. (2007) The Use of Lithium to Prevent or Mitigate Alkali Silica Reaction in Concrete Pavements and Structure. FHWA-HRT-06-133, US Dept. of Transportation, Federal Highway Administration, Washington DC.

[4] Ramachandran, V.S. (1998) Alkali-Aggregate Expansion Inhibiting Admixtures. Cement and Concrete Composites, 20, 149-161. http://dx.doi.org/10.1016/S0958-9465(97)00072-3

[5] Brykov, A., Anisimova, A. and Rozenkova, N. (2014) The Mitigation of Alkali-Silica Reactions by Aluminum- 
Bearing Substances. Materials Sciences and Applications, 5, 363-367. http://dx.doi.org/10.4236/msa.2014.56041

[6] Myrdal, R. (2007) Accelerating Admixtures for Concrete. State of the Art: SINTEF Report N SBF BK A07025, Trondheim.

[7] Brykov, A., Vasilev, A. and Mokeev, M. (2013) Hydration of Portland Cement in the Presence of AluminumContaining Setting Accelerators. Russian Journal of Applied Chemistry, 86, 793-801. http://link.springer.com/article/10.1134/S1070427213060013

[8] Brykov, A., Vasilev, A. and Mokeev, M. (2013) The Impact of Aluminum-Containing Set Accelerators on Sulfate Resistance of Portland Cement Compositions. Materials Sciences and Applications, 4, 29-34. http://dx.doi.org/10.4236/msa.2013.412A005

[9] Paglia, C., Wombacher, F., Böhni, H. and Sommer, M. (2002) An Evaluation of the Sulfate Resistance of Cementitious Material Accelerated with Alkali-Free and Alkaline Admixtures: Laboratory vs. Field. Cement and Concrete Research, 32, 665-671. http://dx.doi.org/10.1016/S0008-8846(01)00739-6

[10] Taylor, H. (1997) Cement Chemistry. Thomas Telford, London.

[11] Menendez, E., Matschei, T. and Glasser, F. (2013) Sulfate Attack of Concrete. In: Alexander, M., et al., Eds., Performance of Cement-Based Materials in Aggressive Aqueous Environments, RILEM State-of-the-Art Reports 10, 7-74. http://dx.doi.org/10.1007/978-94-007-5413-3_2

[12] Hills, L. and Johansen, V. (2007) Hexavalent Chromium in Cement Manufacturing: Literature Review. SN2983, Portland Cement Association, Skokie.

[13] Ramachandran, V.S. (1995) Admixture Formulations. In: Ramachandran, V.S., Ed., Concrete Admixtures Handbook, Noyes Publications, Park Ridge, 1153.

[14] Rawal, A., Smith, B., Athens, G., et al. (2010) Molecular Silicate and Aluminate Species in Anhydrous and Hydrated Cements. Journal of the American Chemical Society, 132, 7321-7337. 